\title{
Numerical Simulation of Blast Vibration and Crack Forming Effect of Rock-Anchored Beam Excavation in Deep Underground Caverns
}

\author{
XinPing Li, ${ }^{1}$ JunHong Huang, ${ }^{2}$ Yi Luo, ${ }^{1}$ Qian Dong, ${ }^{2}$ YouHua Li, \\ Yong Wan, ${ }^{3}$ and TingTing Liu ${ }^{1,4}$ \\ ${ }^{1}$ Hubei Key Laboratory of Road-Bridge and Structure Engineering, Wuhan University of Technology, Wuhan 430070, China \\ ${ }^{2}$ School of Civil Engineering and Architecture, Wuhan University of Technology, Wuhan 430070, China \\ ${ }^{3}$ Three Gorges Construction Engineering Co., Ltd., China Gezhouba Group, Yichang 443000, China \\ ${ }^{4}$ State Key Laboratory of Geomechanics and Geotechnical Engineering, Institute of Rock and Soil Mechanics, \\ Chinese Academy of Sciences, Wuhan, Hubei 430071, China
}

Correspondence should be addressed to Yi Luo; yluo@whut.edu.cn

Received 25 December 2016; Accepted 28 February 2017; Published 23 April 2017

Academic Editor: Tai Thai

Copyright (C) 2017 XinPing Li et al. This is an open access article distributed under the Creative Commons Attribution License, which permits unrestricted use, distribution, and reproduction in any medium, provided the original work is properly cited.

\begin{abstract}
Aiming at surrounding rock damage induced by dynamic disturbance from blasting excavation of rock-anchored beam in rock mass at moderate or far distance in underground cavern, numerical model of different linear charging density and crustal stress in underground cavern is established by adopting dynamic finite element software based on borehole layout, charging, and rock parameter of the actual situation of a certain hydropower station. Through comparison in vibration velocity, contour surface of rock mass excavation, and the crushing extent of excavated rock mass between calculation result and field monitoring, optimum linear charging density of blast hole is determined. Studies are also conducted on rock mass vibration in moderate or far distance to blasting source, the damage of surrounding rock in near-field to blasting source, and crushing degree of excavated rock mass under various in situ stress conditions. Results indicate that, within certain range of in situ stress, the blasting vibration is independent of in situ stress, while when in situ stress is increasing above certain value, the blasting vibration velocity will be increasing and the damage of surrounding rock and the crushing degree of excavated rock mass will be decreasing.
\end{abstract}

\section{Introduction}

Jinsha River Basin, which lies on the upstream of Yangtze River in China, has witnessed the development and construction of large numbers of water conservancy and hydropower projects. Due to the fact that most basin area of Jinsha River locates on the towering and steep mountains, the work of layout, construction, and operation of building hub should be conducted by the framework of underground cavern. Meanwhile, a certain amount of underground caverns in a large-scale and ultra-large type appear along with the enlargement of hydropower in scale. The rock-anchored beam is frequently used as the load bearing of crane in caverns in order to reduce the span of underground powerhouses and accelerate the progress of construction.
The rock-anchored beam is widely used in hydropower projects as the essential construction in underground caverns which makes the first success in Norway $[1,2]$. There is certainly no need for the existence of crane columns or walls in the application of rock-anchored beam since it can take full advantage of the bearing capacity of surrounding walls. The application of rock-anchored beam has several advantages. It can not only reduce the excavation span of underground caverns which benefits the surrounding rock stability and the amount of excavation of tunnels but also make it possible to install the crane in advance and brings convenience for concrete placements of caverns and unit installation. Thus, the construction progress could be accelerated and the investment could be saved, bringing remarkable economical 
benefits. The application of rock-anchored beam is widespread in many large-scale overseas hydropower stations [3].

However, with considerable difficulty, the excavation of rock-anchored beams is in high quality requirements, which directly affects the operation conditions of bridge cranes after construction. In order to make cracks form successfully in adjacent blast holes and reduce the damage of remaining rock mass to minimum, the construction site usually meets the requirements of excavation by means of controlling the charging of the blast hole and blast holes spacing.

Considering the noncoupling charge structure applied in driving blasting, it is the most reasonable to adopt the fluidstructure interaction algorithm to simulate the blasting process [4]. In the simulation of explosion process, by adopting Euler algorithm when it comes to the explosive and noncoupling air in blast holes, explosive could mingle with air unit as fluid. Meanwhile, by adopting Lagrange algorithm aiming at mass rock structures, the interaction between fluid and solid is dealt with by means of fluid-structure coupling. The advantages of this kind of algorithm mare that explosive and fluid materials flow in the Euler unit without the problem of element distortion and the interaction between fluid and solid is dealt with by means of fluid-structure coupling $[5,6]$. When the explosive blast hole blasts, explosive stress wave and detonation gas take effects on the surrounding rock, which makes the cracks on blast hole walls crack and drives their expansion, therefore, forming the penetrating cracks on lines of centers of blast holes and making detonation gas pressure acting on both sides of the cracks.

But the aforesaid algorithms could only simulate the shock response of the near-field of blasting source. There is still a way to go for the simulation of the whole process from the blasting of near-field of blasting source to the blasting vibration spreading of explosion of far-field [7]. The reason is that the explosive material units and meshes around blast holes in the model needed in such algorithm are mapped incredibly small. Furthermore, the calculation model of numerical simulation of explosive vibration field is quite large. All the above factors lead to the heavy amounts of units after the meshing, which would further hamper the progress of calculation. In order to meet the demands of practical application, an equivalent simulation is strongly needed.

In recent years, Ma et al. [8] and $\mathrm{Wu}$ et al. [9] managed to ascertain the changing course of blast holes pressure through calculation as well as with the assistance of laboratory and field test. However, there is still a way to go for these achievements to resolve the problem of blast holes pressure theoretically. In practical application of programs, the selecting of changing courses of blast holes pressures is still semitheoretical and semiexperimental exponential decay load. Generally speaking, exerting the explosion load on the blast holes walls or exerting the explosion load on the surface where lines of centers of blast holes lie on are two frequently used equivalent simulation methods $[10,11]$. According to Saint-Venant principle, the latter method is more reasonable and effective, which adopts triangle pulse waves as equivalent blasting loads to conduct the three-dimensional simulations.
The paper is based on the basic mechanical properties and blasting parameters of rock mass in the process of excavation program of underground caverns in Baihetan hydropower station in Yunnan, China. First, the research adopts threedimensional models in the calculation of vibration speed of the blasting of rock mass in the moderate and far distance and two-dimensional models in the simulation of crushing conditions of rock mass in near-field of blasting sources and explosion. At the same time, the research also includes the comparison of contour surface and vibration speed in the measuring point between the model and the filed. Then, the paper does the study of rock mass vibration in the moderate or far distance of blasting, the damage of surrounding rock in near-field of blasting source, and crushing degree of excavated rock mass under different crustal stress.

\section{The Calculation Method of Rock Mass Response under Blasting Load}

This article uses dynamic finite elements analysis software ANSYS/LS-DYNA, which is a typical dynamic finite element calculation software. It does not open source, so the programming code can not be downloaded. The solving equation used in LS-DYNA for dynamic calculation is motion equation:

$$
[M]\{\ddot{u}\}+[C]\{\dot{u}\}+[K]\{u\}=\{f\},
$$

where $[M]$ is global mass matrix, $[C]$ is damping matrix, $[K]$ is global stiffness matrix, $\{\ddot{u}\},\{\dot{u}\}$, and $\{u\}$ are nodes' acceleration vector, velocity vector, and displacement vector, respectively, and $\{f\}$ is equivalent nodal force vector [13].

ANSYS uses Newmark integration method to solve kinetic equation. It's basic idea is to change the requirement that any time $t$ should satisfy the displacement vector $u(t)$ of (1) to only require time discrete points $t, t+\Delta t, \ldots$ to satisfy the above equation of motion.

The solving equation used for static calculation is as follows:

$$
[K]\{\delta\}=\{W\},
$$

where $[K]$ is global stiffness matrix, $\{\delta\}$ is displacement field of rock mass, and $\{W\}$ is stress field of rock mass.

Comparing (1) with (2), the solving equation used in static calculation does not contain mass matrix, so it can not reflect the influences that inertia force has on surrounding rock deformation in the whole process of tunnel blast excavation. Xie et al. [14] performed further research about the damage situation of tunnel in the process of blasting excavation by LSDYNA.

2.1. Equivalent Load Application Method. Due to the fact that the blast holes studied in this paper are small in size and large in amount, it is inconvenient to build the blast hole model through the method of explosion load exertion in threedimensional model. According to the equilibrium principle, exerting the peak pressure of shock waves on the blast holes walls is equivalent to the value on lines of centers of blast holes [15]. The disturbances of rock mass under explosion 


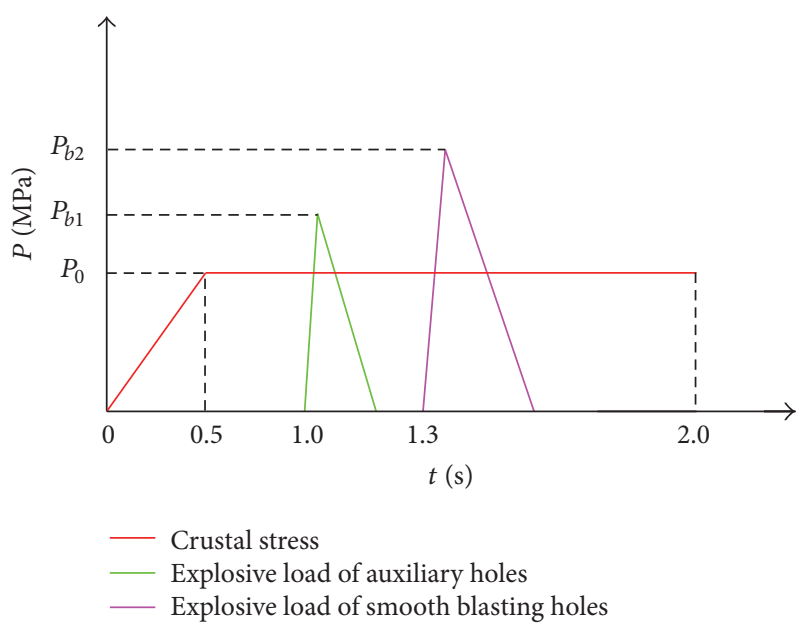

Figure 1: The curved diagram of explosion load.

load mainly depend on the peak load produced by blasting and the affecting time of explosion load. The paper simplifies the explosion load curve to triangle load which is exerted on blast holes walls. The explosion load curve is shown in Figure 1.

Overseas scholars have come up with C-J theory, which simplifies the detonation wave to strong discontinuity surface contained chemical reactions and gives the conclusion of stable spread of detonation wave under the circumstances of C-J conditions. The simplified load peak value $p_{b}$ exerting on blast holes is

$$
p_{b}=n \cdot \frac{\rho_{0} D^{2}}{2(1+\gamma)}\left(\frac{d_{c}}{d_{b}}\right)^{2 \gamma}\left(\frac{l_{e}}{l_{b}}\right)^{\gamma},
$$

where $\rho_{0}$ represents the density of explosive $\left(\mathrm{g} / \mathrm{cm}^{3}\right) ; D$ represents explosive velocity $(\mathrm{m} / \mathrm{s}) ; \gamma$ represents the isentropic exponent of explosive, usually takes $3 ; d_{c}$ represents the charge diameter; $d_{b}$ represents borehole diameter; $l_{e}$ represents the length of blast holes; $l_{b}$ represents the length of charge column; here smooth blasting holes take $l_{e}=0.6 l_{b}$ and auxiliary holes take $l_{e}=0.8 l_{b} ; n$ represents pressure increasing factor when the detonation gas expansion collides with hole wall, $n=8-11$, and it takes 10 for emulsion explosive.

As shown in Figure 2, the equivalent peak pressure calculated through force balance principle is

$$
p_{e}=\frac{2 r_{0}}{a} p_{b}
$$

where $r_{0}$ represents blast hole radius; $a$ represents distances between blast holes.

\subsection{The Principle of Rock Mass Damage under Explosion} Action. The principle of rock mass damage depends on the property of rock mass as well as the practical force conditions. The pressure of rock mass, taking the Mises damage rule, forms the crushing area of rock mass blasting, while the

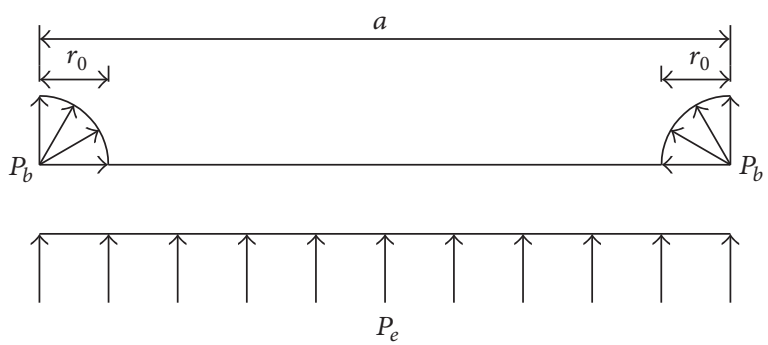

FIgURE 2: The equivalent load exerting on lines of centers of blast holes.

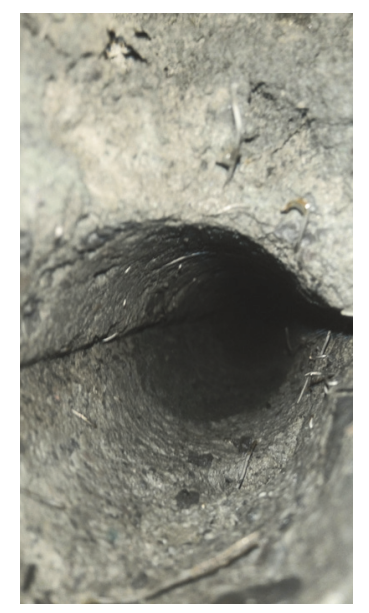

Figure 3: Grooved blast holes.

cracks area is the result of the damage of tensile force. The damage rule of rock mass is as follows:

$$
\begin{aligned}
\sigma_{\mathrm{VM}} & >\sigma_{c d}, \quad(\text { crushs area }), \\
\sigma_{t} & >\sigma_{t d}, \quad(\text { cracks area }), \\
\sigma_{\mathrm{VM}} & =\sqrt{\frac{3}{2} \sigma_{i j} \sigma_{i j}},
\end{aligned}
$$

where $\sigma_{\mathrm{VM}}$ is the von Mises effective stress of any point in rock mass; $\sigma_{i j}(i, j=1,2,3)$ is the stress components of rock mass; $\sigma_{t}$ is the tensile stress of explosion load of any point in rock mass; $\sigma_{c d}, \sigma_{t d}$ are known as uniaxial dynamic compressive strength and tensile strength of rock mass, respectively.

In order to reduce the damage of surrounding rock on site, grooving has been done on part of blast holes as shown in Figure 3. The design of grooved blast holes in models according to the actual grooved blast holes sizes on site is shown in Figure 4. The next Figure 5 is explosion load figure of the groove borehole wall and the circular part of borehole wall is main pressure effect, while the groove tip of borehole wall is mainly tensile effect.

As shown in Figure 5, during the detonation of explosives in borhole, tensile stress would be concentrated at groove 


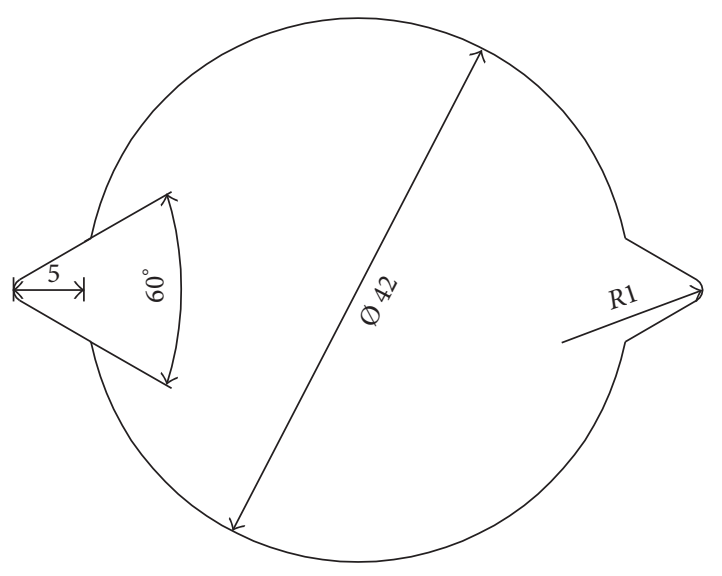

Figure 4: Grooved blast holes size.

tip $A$ instantaneously, and crack initial from element $A$ must satisfy the formula

$$
\begin{aligned}
& T>\sigma_{t d}, \\
& T=P_{r} \cos \left(\frac{\alpha}{2}\right) .
\end{aligned}
$$

The dynamic compressive stress of rock increases with the improvement of loaded strain rate, generally approximated by the following equation [16]:

$$
\sigma_{c d}=\sigma_{c} \dot{\varepsilon}^{1 / 3},
$$

where $\sigma_{c}$ in the equation refers to the uniaxial static compressive stress of rock.

The loaded strain rate of rock $\dot{\varepsilon}$ in blasting during programs is within $10^{0}-10^{5} \mathrm{~s}^{-1}$, among which the strain rate in crushed zones could be $\dot{\varepsilon}=10^{2}-10^{4} \mathrm{~s}^{-1}$ and in cracked zones could be $\dot{\varepsilon}=10^{0}-10^{3} \mathrm{~s}^{-1}$.

For the lack of corresponding analytical data of experiments and theories, the value of dynamic tensile strength approximates

$$
\sigma_{t d}=\sigma_{t} \dot{\varepsilon}^{1 / 3},
$$

where $\sigma_{t}$ in the equation refers to the uniaxial static tensile strength of rock mass.

The paper applies the fluid-structure interaction algorithm on the calculation of explosive, rock, and air through two-dimensional model, taking the tensile strength of rock as the criteria of rock mass fracture, in order to observe the damage of surrounding rock and the crushing condition of excavated rock mass under the circumstances of noncoupling charge. The damage and crushing rate of rock mass under the effect of blast by explosive have long been researched. Both domestic and overseas scholars have drawn quite a few remarkable conclusions through experimental research and theoretical analysis. However, these conclusions differ from one another due to the differences between experimental conditions. The paper will research on the damage of rock mass and crushing rate under different crustal stress with the reference of actual operation situation on site.
2.3. Plastic Kinematic Strengthened Constitutive Model. In rock medium, the analysis of static problems is based on isotropic strengthened constitutive model, while the analysis of cyclic loading and dynamic issue is based on two constitutive models, namely, the kinematic strengthened constitutive and the mixed strengthened constitutive models. Particularly, during the blasting process, under the conditions of comparable large strain of rock mass in near-field, the effect of strain rate is quite apparent. Considering the aforesaid factors, it is more appropriate to build the model of plastic kinematic strengthened constitutive in the analysis of dynamic problems of underground blasting programs, for the model conforms with the conditions in real project. The strain rate is considered in Cowper-Symonds model; the yield stress is expressed in factors related to the strain rate [17]; and the criteria of material which yields in the model of plastic kinematic strengthened constitutive are as follows:

$$
\begin{aligned}
\phi & =\sigma_{i}^{2}-\sigma_{y}^{2}=0, \\
\sigma_{y} & =\left[1+\left(\frac{\dot{\varepsilon}}{C}\right)^{1 / P}\right]\left(\sigma_{0}+\beta E_{p} \varepsilon_{p}^{\mathrm{eff}}\right), \\
E_{p} & =\frac{E_{0} E_{\mathrm{tan}}}{E_{0}-E_{\mathrm{tan}}} .
\end{aligned}
$$

In the formula, $\dot{\varepsilon}$ is strain rate and $C$ and $P$ are relative parameters in Cowper-Symonds, which are generally determined by features of material strain rate. The paper refers to the conclusion in reference [17], which indicates that $C$ is $2.5 \mathrm{~s}^{-1}, P$ is $4, \sigma_{0}$ represents initial yield stress of rock, and $\beta$ is the hardening coefficient. When $\beta=0, \beta$ represents plastic kinematic hardening; when $\beta=1$, it represents isotropic hardening; when $0<\beta<1$, it represents mixed hardening. The paper adopts the plastic following hardening in calculation; therefore, $\beta=0$ is taken. $E_{p}, E_{0}$, and $E_{\tan }$ represent plastic strain-hardening modulus, Young's modulus, and tangent modulus separately.

When the material is in hardening stage, the efficient plastic strain rate $\varepsilon_{\text {eff }}^{p}$ corresponded could be expressed as follows:

$$
\begin{aligned}
& \varepsilon_{\mathrm{eff}}^{p}=\int_{0}^{t}\left(\frac{2}{3} \dot{\varepsilon}_{i j}^{p} \dot{\varepsilon}_{i j}^{p}\right)^{1 / 2} d t, \\
& \dot{\varepsilon}_{\mathrm{eff}}^{p}=\dot{\varepsilon}_{i j}-\dot{\varepsilon}_{i j}^{e},
\end{aligned}
$$

where $\dot{\varepsilon}_{i j}^{p}$ and $\dot{\varepsilon}_{i j}^{e}$ represent plastic strain rate and elastic strain rate separately.

\section{The Numerical Model of Blasting Excavation of Rock-Anchored Beam}

Baihetan hydropower station, located in the upstream of Jinsha River in southwest China, has a capacity of 2060 billion cubic meters in reservoir and the underground powerhouses install 16 hydroelectric generating sets with the capacity per set of $1000 \mathrm{MW}$. The installed capacity drafted in the beginning is 16 million $\mathrm{KW}$, and the average annual electric 

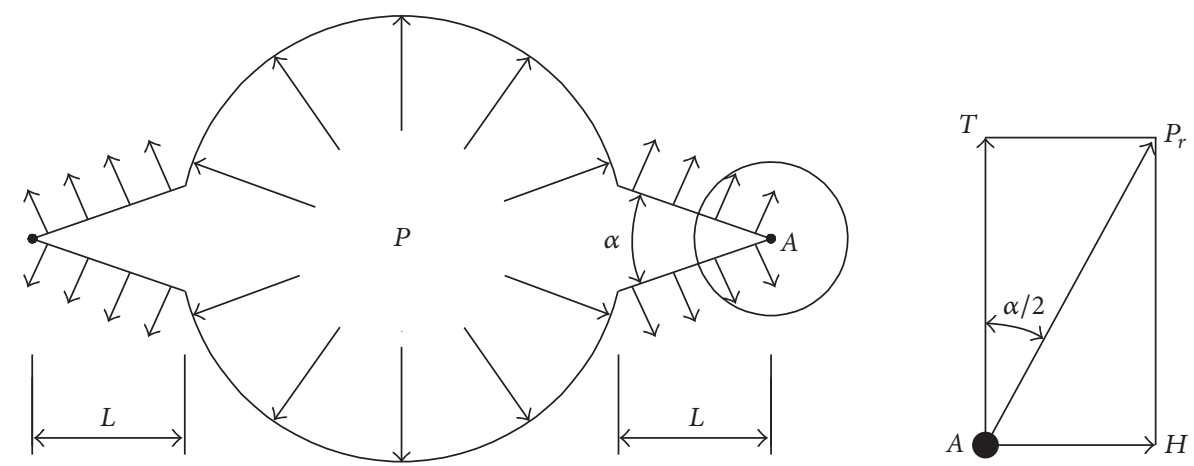

FIGURE 5: Hole wall of groove hole load distribution.
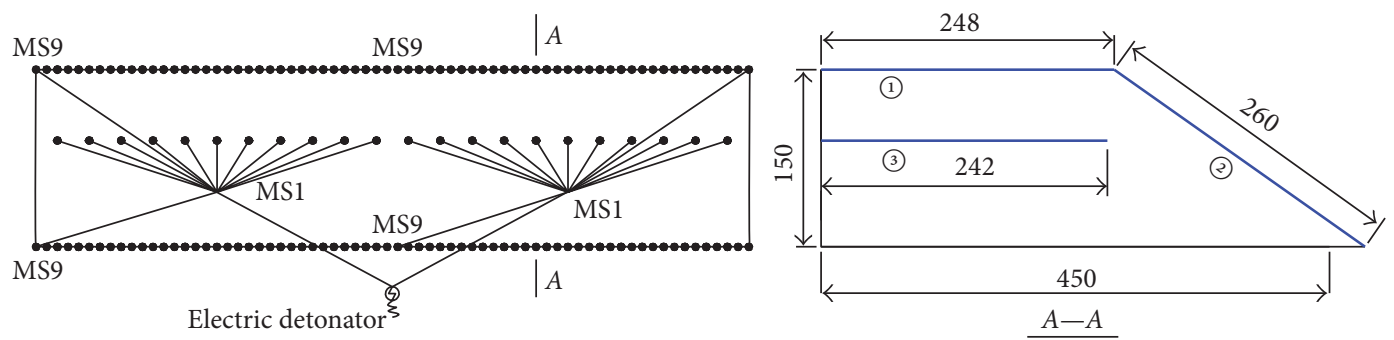

Figure 6: The plane figure of blast holes detonation network and the profile map of blast holes (unit: $\mathrm{cm}$ ).

energy production is 6024 billion KWH. The station will become the second largest hydropower station which is next only to Three Gorges after completion, which makes the high demand of quality of rock-anchored beam of rock mass in underground plants. Thus, there is strong need for the fine control of blasting excavation of the rock-anchored beam in order to keep the damage of surrounding rock caused by blasting in a small extent.

The charging parameter of blast holes in single blasting excavation on site is shown in Table 1. Electronic detonator is used for initiation delay to reduce the blasting vibration and improve the effect of rock fracture in many engineering experiments $[18,19]$, and at present the minimum delay has already reached $1 \mathrm{~ms}$, so I used MS1 and MS9 electronic detonators to achieve initiation delay for auxiliary blasting holes and smooth blasting holes. The plane figure of blast holes detonation network and the profile map of blast holes are shown in Figure 6.

\subsection{The Three-Dimensional Model of the Blasting Excavation of} Rock-Anchored Beam. Taking the blasting excavation of the protective layers of rock-anchored beams in the underground main power house of the right bank of the dam as an example, the blasting excavation of protective layers of rockanchored beams drills the vertical smooth blasting holes, oblique smooth blasting holes, and auxiliary blast holes manually in the rate of $20.4 \mathrm{~m}$ excavation length each time. Meanwhile, the blasting vibration monitoring is conducted on the sidewalls near excavated rock-anchored beams. The measuring point vibration monitoring of near-field rock during the process of blasting excavation is conducted in

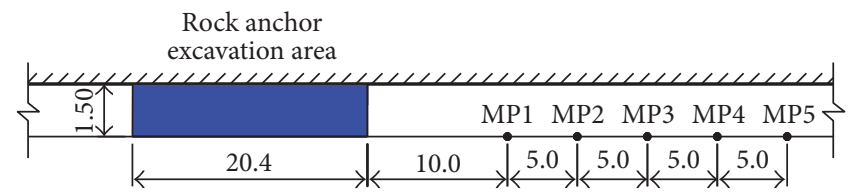

Figure 7: The schematic diagram of measuring point layout of blast vibration velocity (unit: $\mathrm{m}$ ).

order to make sure the disturbances of blasting excavation to surrounding rocks in a safety range. Meanwhile, for ascertaining the safety of monitoring equipment, the nearest measuring points are arranged $10 \mathrm{~m}$ away from the boundary of the excavation area, and then one measuring point is arranged every $5 \mathrm{~m}$, and a total of five measuring points are arranged. It is as shown in Figure 7.

The elevation of rock-anchored beams excavated on site ranges from EL. $602.40 \mathrm{~m}$ to EL. $606.90 \mathrm{~m}$. Part of blast holes are grooved to ensure the quality of excavation and observe the protection effect on surrounding rock compared with circular blast holes. Figure 8 is the front view and side view of excavation area and monitoring point area of rockanchored beam blasting. The vertical crustal stress of rock mass in excavation area is $12 \mathrm{MPa}$ and horizontal crustal stress is $21 \mathrm{MPa}$. The blasting load is directly exerted on the lines of centers of blast holes, so the model of protecting layer of rock-anchored beam only builds the part between lines of centers of auxiliary blast holes to those of main blast holes. Exert vertical crustal stress on the above and right plane of model, vertical restraints on bottom, left and back plane, 
TABLE 1: Different blast hole layout and charge parameter.

\begin{tabular}{lcccccc}
\hline Name & Hole diameter & Hole distance & Hole depth & Hole amount & Cartridge diameter & Charging density \\
\hline (1) Vertical holes & $\Phi 42 \mathrm{~mm}$ & $30 \mathrm{~cm}$ & $248 \mathrm{~cm}$ & 68 & $\Phi 25 \mathrm{~mm}$ & $65 / 70 / 85 \mathrm{~g} / \mathrm{m}$ \\
(2) Oblique holes & $\Phi 42 \mathrm{~mm}$ & $30 \mathrm{~cm}$ & $260 \mathrm{~cm}$ & 68 & $\Phi 25 \mathrm{~mm}$ & $65 / 70 / 85 \mathrm{~g} / \mathrm{m}$ \\
(3) Auxiliary holes & $\Phi 42 \mathrm{~mm}$ & $90 \mathrm{~cm}$ & $242 \mathrm{~cm}$ & 22 & $\Phi 25 \mathrm{~mm}$ & $186 / 206 / 250 \mathrm{~g} / \mathrm{m}$ \\
\hline
\end{tabular}
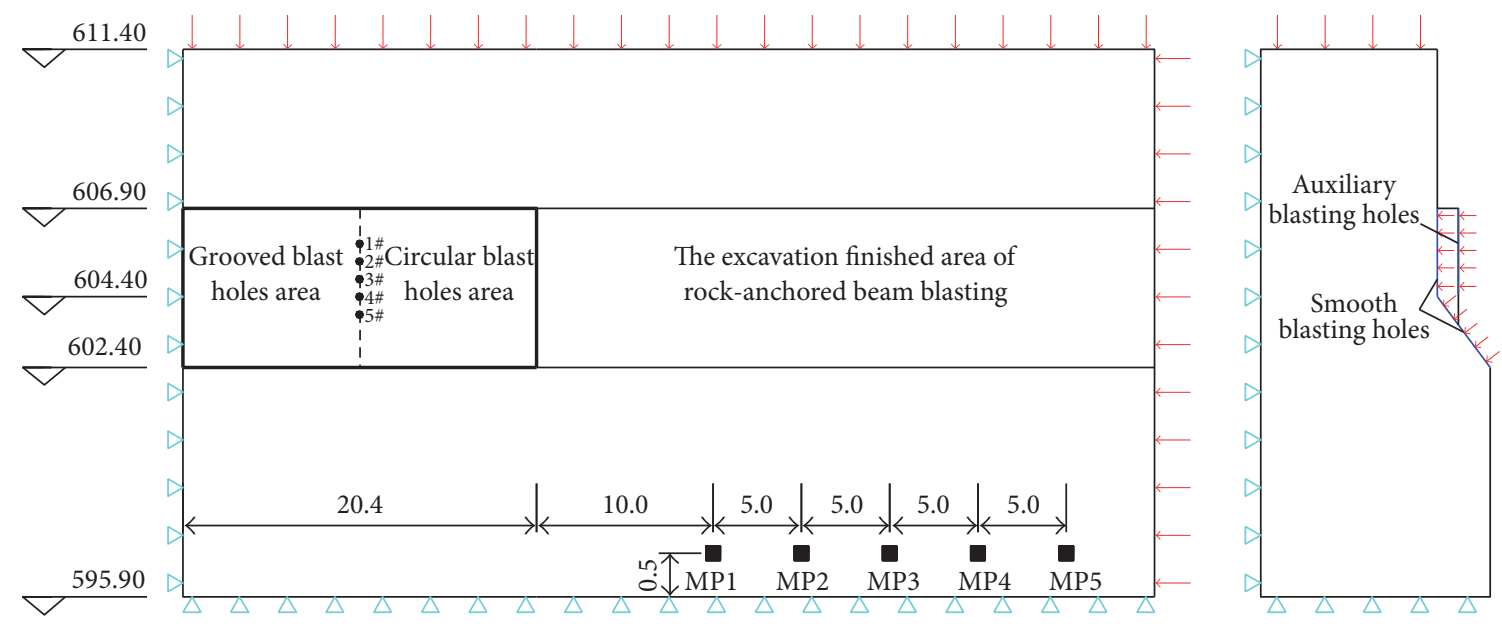

FIgURE 8: The front view and side view of blasting test of rock-anchored beam (unit: $\mathrm{m}$ ).

TABLE 2: Rock mass physical and mechanical material.

\begin{tabular}{lccccc}
\hline$\rho_{1} /\left(\mathrm{g} / \mathrm{cm}^{3}\right)$ & $E_{0} / \mathrm{GPa}$ & $\mu$ & $\sigma_{t} / \mathrm{MPa}$ & $\sigma_{c} / \mathrm{MPa}$ & $E_{\mathrm{tan}} / \mathrm{GPa}$ \\
\hline 2.7 & 50.0 & 0.22 & 6.0 & 78.0 & 8.0 \\
\hline
\end{tabular}

Among them, $\rho_{1}$ represents the density of rock mass; $E_{0}$ represents Young's modulus of rock mass; $\mu$ represents Poisson's ratio; $\sigma_{t}$ represents the tensile strength of rock mass. $\sigma_{c}$ represents the compress strength of rock mass. $E_{\text {tan }}$ represents the tangent modulus of rock mass.

and nonreflected border condition on each plane besides free surface.

The rock parameter [20] of rock-anchored beam of underground caverns based on the field survey dates is shown in Table 2.

According to the construction design of the main underground powerhouse, the dynamic finite element program is used to establish the calculation model shown in Figure 9 with the reference of Figure 8. The model is $14.5 \mathrm{~m}$ in height, $55 \mathrm{~m}$ in width, and $5 \mathrm{~m}$ in thickness. The blasting load is exerted on lines of centers of auxiliary holes first and then on lines of centers of smooth blasting holes.

\subsection{The Two-Dimensional Model of Blasting Excavation of} Rock-Anchored Beam. Due to the fact that the V-shape grooving has been done on part of smooth blasting holes in the blasting excavation process of rock-anchored beam on site, two-dimensional crack forming model of blast holes is added in order to compare the effect of crack forming of grooved blast holes with that of circular blast holes. In the model, the spacing and array pitch of blast holes are shown in Figure 10. The vertical symmetry constraints are exerted
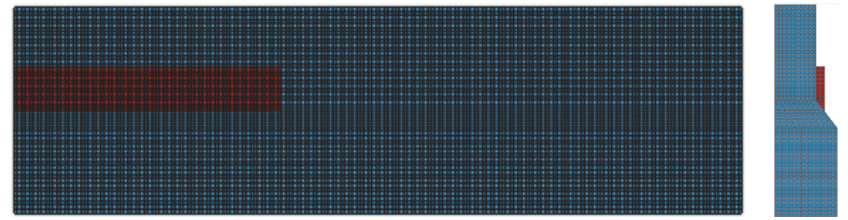

FigURE 9: The front view and side view of calculation model of blasting excavation of rock-anchored beam (unit: $\mathrm{m}$ ).

on front and back planes; the crustal stress is exerted on left plane; the symmetry constraints are exerted on right plane; the nonreflecting boundary and constraints are exerted on upper plane and the bottom is free surface. The two smooth blasting holes on left plane are grooved blast holes and the two on the right plane are circular blast holes.

The state equation of detonation products applies the JWL equation of state [21] specifically set for describing blasting pressure characteristics of energetic material such as explosive; its expression is as follows:

$$
\begin{aligned}
P= & A\left(1-\frac{w}{R_{1} V}\right) e^{-R_{1} V}+B\left(1-\frac{w}{R_{2} V}\right) e^{-R_{2} V} \\
& +\frac{w E_{2}}{V},
\end{aligned}
$$

where $V$ represents relative volume of detonation gas; $A, B$, $R_{1}, R_{2}, w$, and $E_{2}$ all represent material parameters of the state equation.

The specific parameters of rock emulsion explosive in model and the JWL state equation are shown in Table 3. 


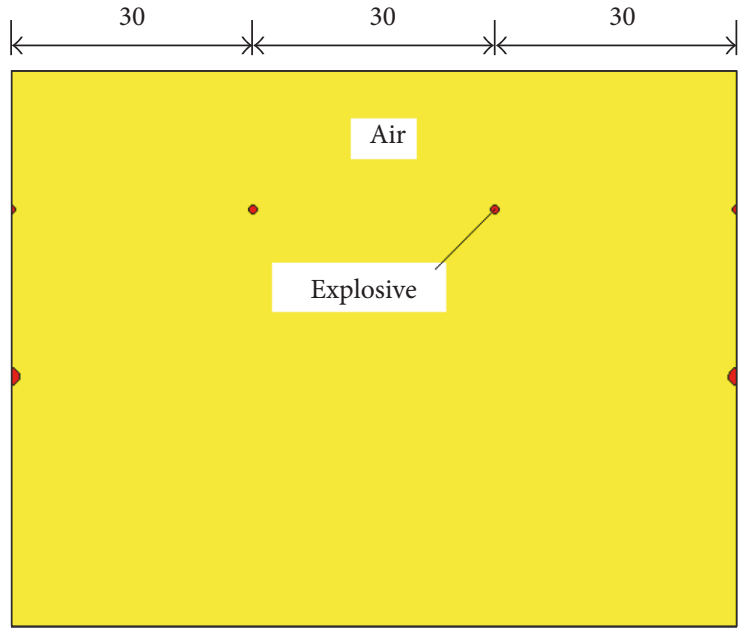

(a) Size diagram of explosive and air

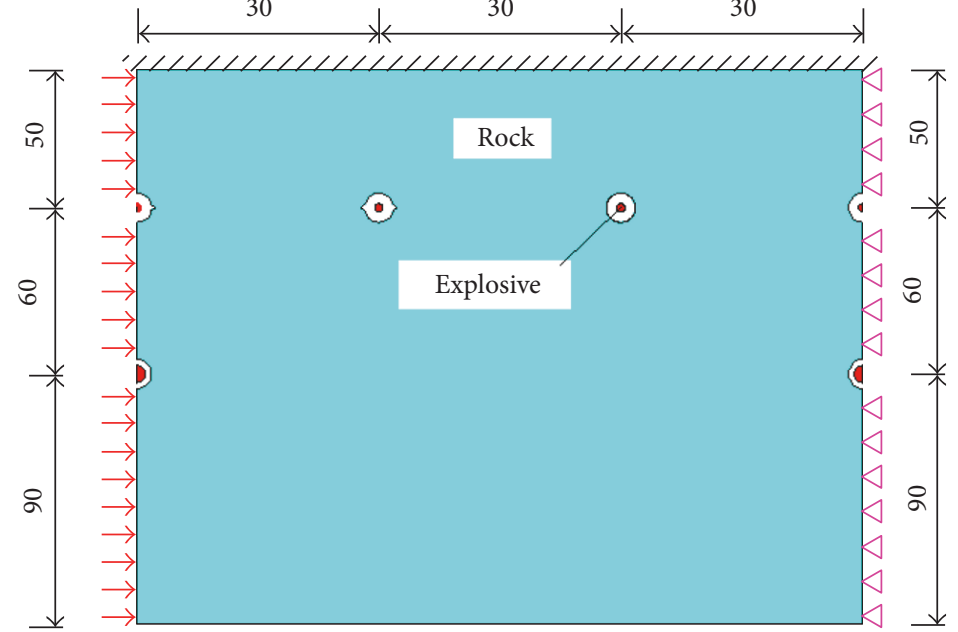

(b) Size diagram of explosive and rock

FIgURE 10: The calculation model of two-dimensional plane (unit: $\mathrm{cm}$ ).

TABLE 3: Explosive and JWL state equation parameters [12].

\begin{tabular}{lcccccc}
\hline$D /(\mathrm{m} / \mathrm{s})$ & $A / \mathrm{Gpa}$ & $B / \mathrm{Gpa}$ & $R_{1}$ & $R_{2}$ & $w$ & $E_{2} /(\mathrm{J} / \mathrm{m})$ \\
\hline 3200 & 214 & 0.18 & 4.15 & 0.95 & 0.15 & $4.19 \times 10^{9}$ \\
\hline
\end{tabular}

Among them, $D$ represents the velocity of detonation wave.

\section{The Comparative Analysis of Computed Results and Monitoring Result}

4.1. The Comparative Analysis of Numerical Calculation and Measured Results Blasting Vibration Velocity. Conducting three groups of numerical calculations according to the linear charging density on site, calculations of three groups of equivalent load are based on formulas (1) and (2) and the parameters in Table 1 . The results of smooth blasting holes are expressed as (a) 17.9 MPa, (b) $19.3 \mathrm{MPa}$, and (c) $23.4 \mathrm{MPa}$ while those of auxiliary blasting holes are (a) $14.1 \mathrm{MPa}$, (b) 15.2 $\mathrm{MPa}$, and (c) $18.5 \mathrm{MPa}$. The three groups of blasting load are exerted on lines of centers of smooth blasting holes as well as those of auxiliary blast holes, respectively.

Through extracting the vibration velocity on measuring points shown in Figure 8 through postprocessor and making a comparison with that on same points on site, as shown in Figure 11. It will take a lot of space to compare every measuring points' wave velocity curves, so here comparison and analysis of only the first $0.5 \mathrm{~s}$ of MP1 are done, during which the vibration velocity is large, and the equivalent load of blast hole is 17.9 Mpa-14.1 Mpa. From Figures 11(a), 11(b), and 11(c) it can be seen that there will be a peak vibration velocity of measuring points after auxiliary blast holes detonate first and a bigger peak value after smooth blast holes detonate. Then the comparative analysis of peak vibration velocity on measuring points by numerical simulation and site measurement is conducted in three directions. It is shown on the Figures $11(\mathrm{~d}), 11(\mathrm{e})$, and 11(f) that the vibration variation trends in different directions are similar on conditions of the same linear charging density. Furthermore, the vibration velocity on measuring points of numerical simulation approximates that of site measuring. With the increase of linear charging density, vibration velocity of same measuring points will increase correspondingly. Moreover, because the increased value of the vibration velocity on measuring points away from blasting source is relatively small and the vibration velocity of points in a rather near distance is much more affected by linear charging density, in the process of blasting excavation, whether the explosive load of blast holes corresponds the safety standards mainly depends on the values of vibration rate of rock mass, which is close to the blasting source. The vibration velocity of the measuring point at $10 \mathrm{~m}$ away from the blasting sources should be less than $10 \mathrm{~cm} / \mathrm{s}$ [22]. We could conclude from the figure that charging and layout of blast holes on site accord with the regulation.

Selecting one group unit from the rock-anchored beam region of rock mass shown in Figure 5, exerting the average crustal stress suffered from three directions is exerted on twodimensional planform as the original value of crustal stress. As is shown in Table 4, the average unit stress in $X$ direction which is perpendicular to tunnel axis is $0.28 \mathrm{MPa}$; the average unit stress in $Y$ direction is $20.32 \mathrm{MPa}$, and the average unit stress in $Z$ direction which parallels tunnel axis is $20.32 \mathrm{MPa}$. Due to the fact that two-dimensional plane graph is the $X O Z$ planform of three-dimensional diagram, there is no need for the exertion of crustal stress on $Y$ direction. While the stress on $X$ direction is incredible small compared to that on $Z$ direction, therefore, it could be ignored for the convenience of model calculation, only exerting the stress of $Z$ direction on two-dimensional plane graph.

\subsection{The Comparison between Numerical Simulated Crack} Forming Figure and Practical Situation on Site. A comparison is made among the two-dimensional plane figure of cracks and the figures of contour surface and rock mass crushing on site in three values of different linear charging density. 
TABLE 4: Stress values of five measuring points of rock-anchored beam.

\begin{tabular}{lcccccc}
\hline Direction & & \multicolumn{2}{c}{ Measuring points } & $5^{\#}$ & Average value \\
& $1^{\#}$ & $2^{\#}$ & $3^{\#}$ & 0.20 & 0.17 & 0.28 \\
$X / \mathrm{MPa}$ & 0.45 & 0.33 & 0.25 & 13.28 & 13.22 & 13.56 \\
$Y / \mathrm{MPa}$ & 11.55 & 15.92 & 20.81 & 20.22 & 20.43 & 20.32 \\
$Z / \mathrm{MPa}$ & 20.42 & 20.46 & 20.08 & & \\
\hline
\end{tabular}

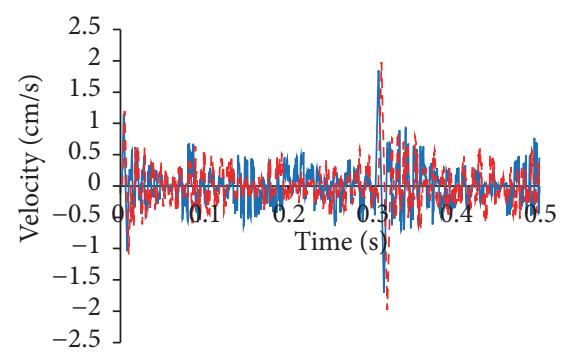

— Numerical simulation $X$

(a) MP1 vibration curve in the $X$ direction

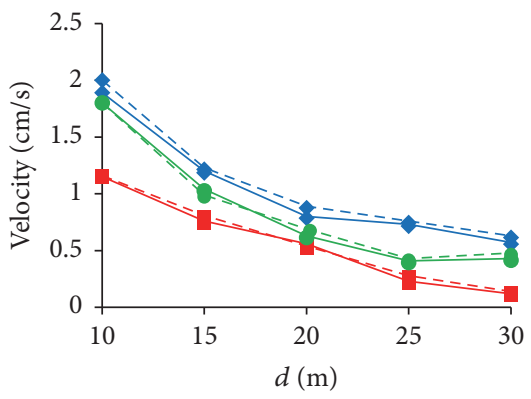

$\multimap$ Numerical simulation $X$

- - Site measurement $X$

$\rightarrow$ Numerical simulation $Y$

- $\square$ - Site measurement $Y$

- Numerical simulation $Z$

- - Site measurement $Z$

(d) Equivalent load 17.9 MPa-14.1 MPa

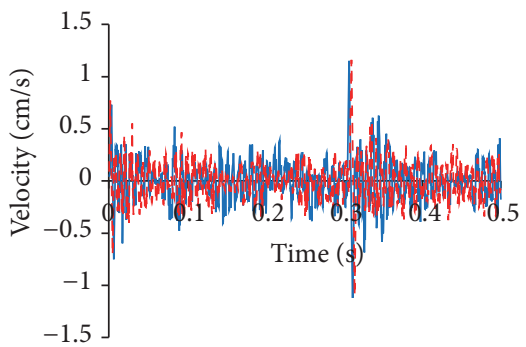

- Numerical simulation $Y$

- - - Site measurement $Y$

(b) MP1 vibration curve in the $Y$ direction

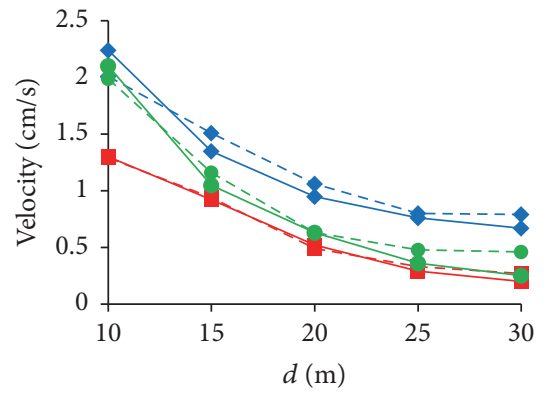

$\multimap$ Numerical simulation $X$

- - Site measurement $X$

$\rightarrow$ Numerical simulation $Y$

- - Site measurement $Y$

- - Numerical simulation $Z$

- - Site measurement $Z$

(e) Equivalent load 19.3 MPa-15.2 MPa

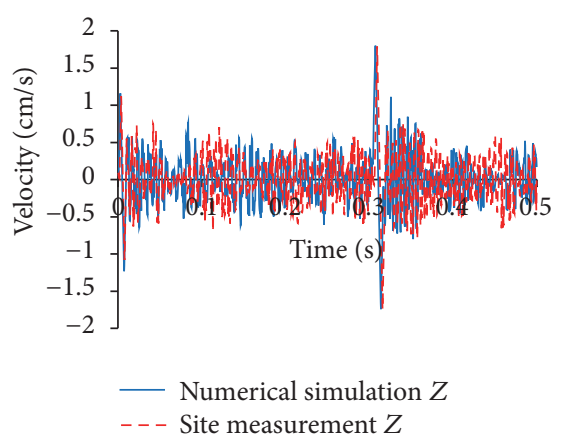

(c) MP1 vibration curve in the $Z$ direction

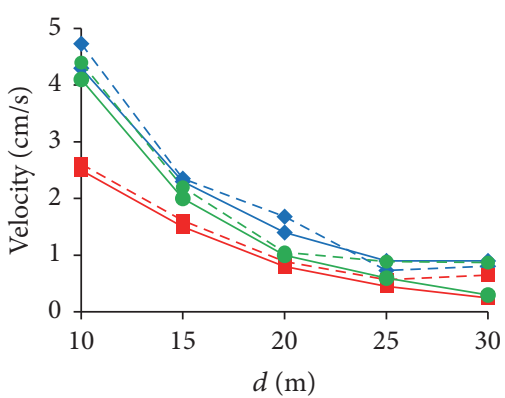

$\multimap$ Numerical simulation $X$

$-\diamond$ - Site measurement $X$

$\rightarrow$ Numerical simulation $Y$

- - Site measurement $Y$

- - Numerical simulation $Z$

- - Site measurement $Z$

(f) Equivalent load $23.4 \mathrm{MPa}-18.5 \mathrm{MPa}$

FIGURE 11: The comparison of vibration velocity of measuring points in numerical simulation and field measurement.

As shown in Figure 12, when, in the same linear charging density, the modeling figure of crack forming consists with the excavation figure on site.

(1) When the linear charging densities of the smooth lasting holes and auxiliary holes are $65 \mathrm{~g} / \mathrm{m}$ and $206 \mathrm{~g} / \mathrm{m}$, respectively, it is shown in the figure that the cracks between grooved smooth blasting holes are quite flat and the damage to surrounding rock is rather small, while there are no penetrating cracks formed between circular smooth blasting holes, which indicates that such charging is too small to form cracks between circular blast holes. However, the grooved blast holes take effect on energy gathering and guiding so as to utilize the more blasting power on crack forming of rock between blast holes. Furthermore, the crushing degree of excavated rock mass is rather small and the boulder frequency is large, so the demand of crushing degree could not be reached.

(2) When the linear charging densities of smooth blast holes and auxiliary holes are $70 \mathrm{~g} / \mathrm{m}$ and $206 \mathrm{~g} / \mathrm{m}$, respectively, penetrating cracks could be formed between blast holes after the blasting. However, cracks between grooved blast holes are more flat than those of circular blast holes, which indicate that penetrating cracks could be formed among blast holes in different shapes under such charging. Moreover, the crushing degree of excavated rock mass is large so it is convenient for the shipment of crushing rock mass.

(3) When the linear charging densities of smooth blast holes and auxiliary holes are $85 \mathrm{~g} / \mathrm{m}$ and $250 \mathrm{~g} / \mathrm{m}$, 

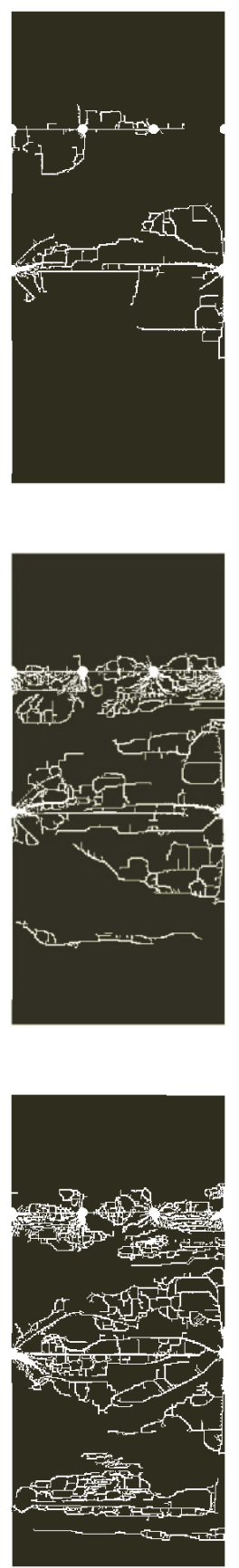

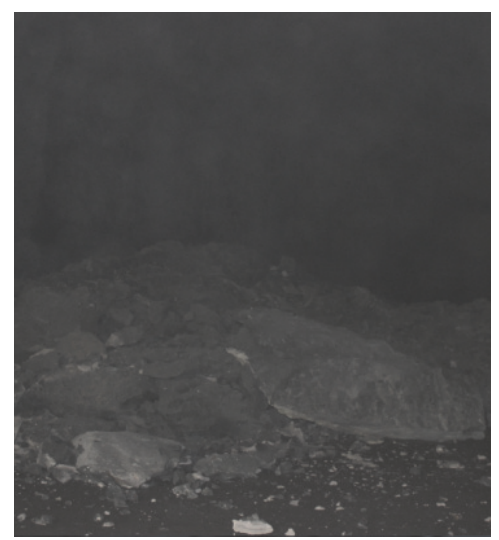

(a) The linear charging density is $65 \mathrm{~g} / \mathrm{m}$
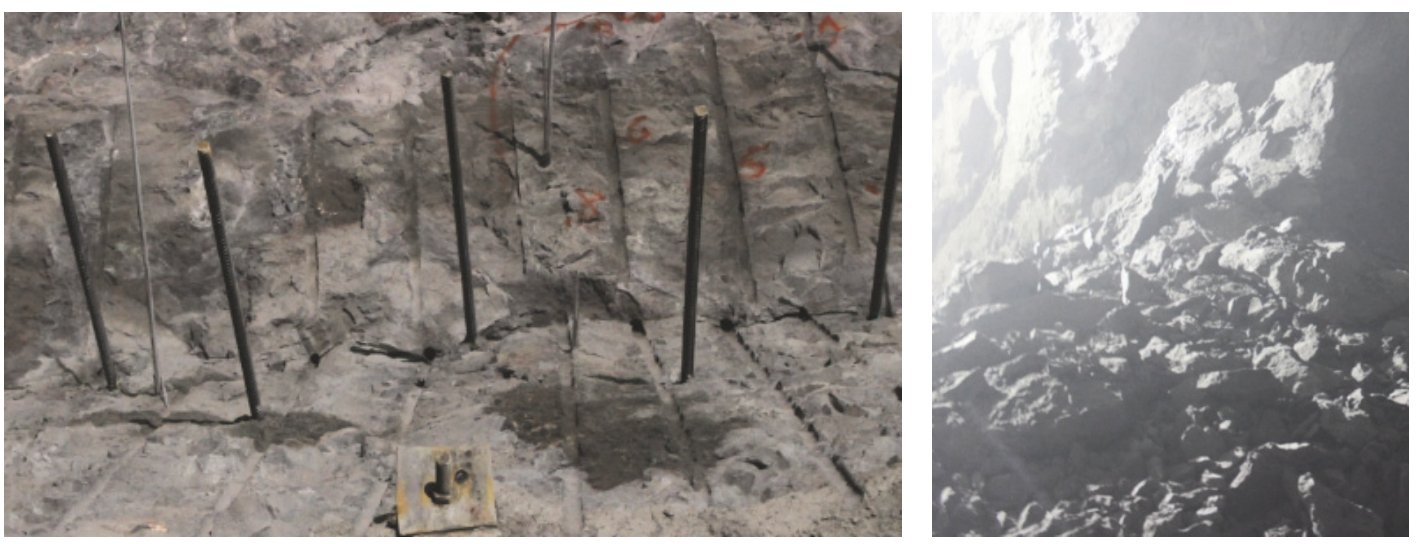

(b) The linear charging density is $70 \mathrm{~g} / \mathrm{m}$
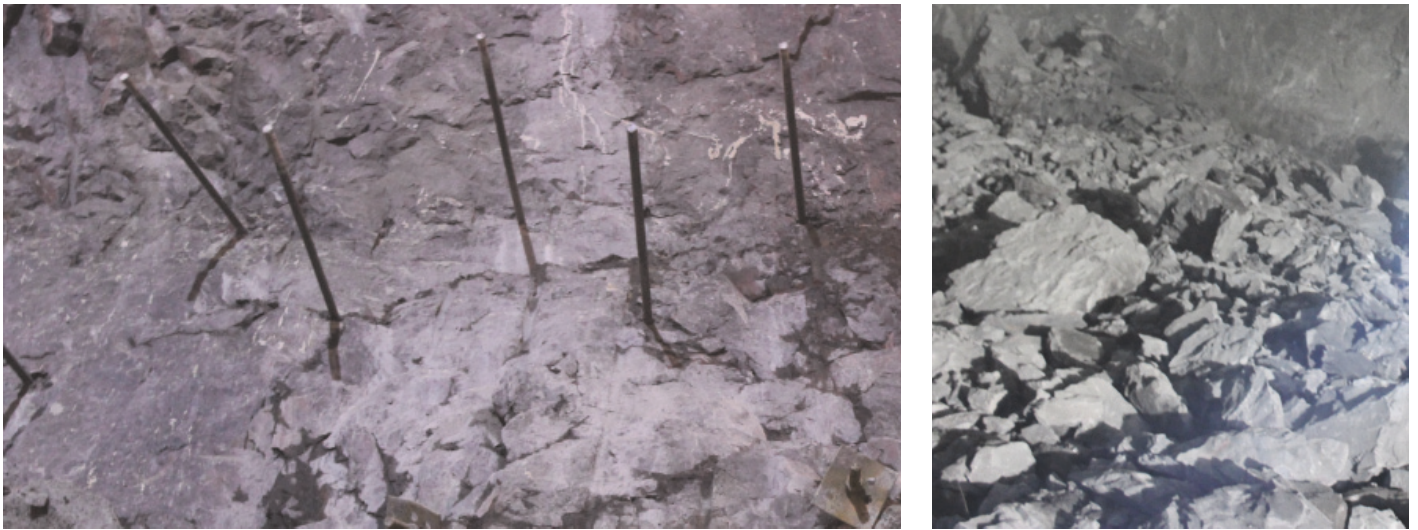

(c) The linear charging density is $85 \mathrm{~g} / \mathrm{m}$

FiguRE 12: The comparison of excavated contour and crushing rate of rock mass in numerical simulation and field measurement under different charge amount.

respectively, besides the cracks forming among smooth blast holes of different shapes, serious damage of surrounding rocks also takes place and the crushing degree of rock mass is rather large.

According to the contour surface of cracks forming on site, the damage reaches the largest extent where vertical smooth blast holes intersect with the oblique ones. The fact consists with the research conclusion of Dong et al. [23]. It indicates that the charging amount of blast holes must be in fine control in order to make sure the oriented cracks forming of grooved blast holes could take place, ensuring the flat and smooth of cracks forming among blast holes and meanwhile reducing the charge amount as much as possible.

Based on the aforesaid analysis, when the linear charging density is $70 \mathrm{~g} / \mathrm{m}$, the penetrating cracks could be formed among smooth blasting holes and the damage to surrounding rocks is in low extent. Furthermore, when grooved blast hole 


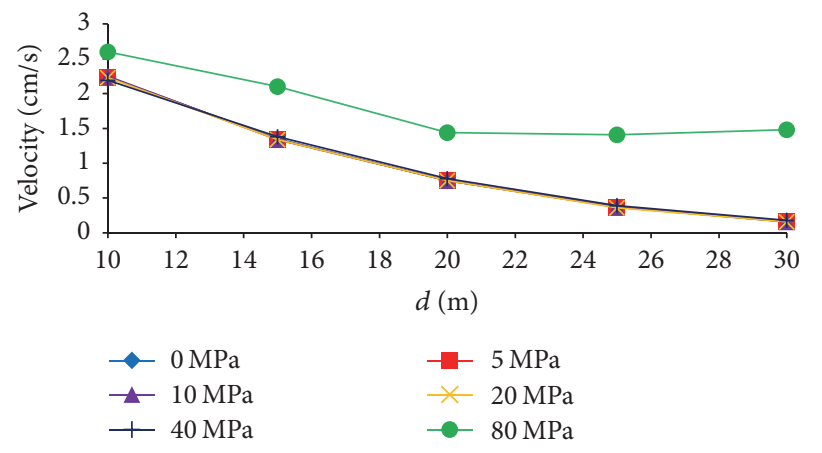

(a) Perpendicular to tunnel axis direction $X$

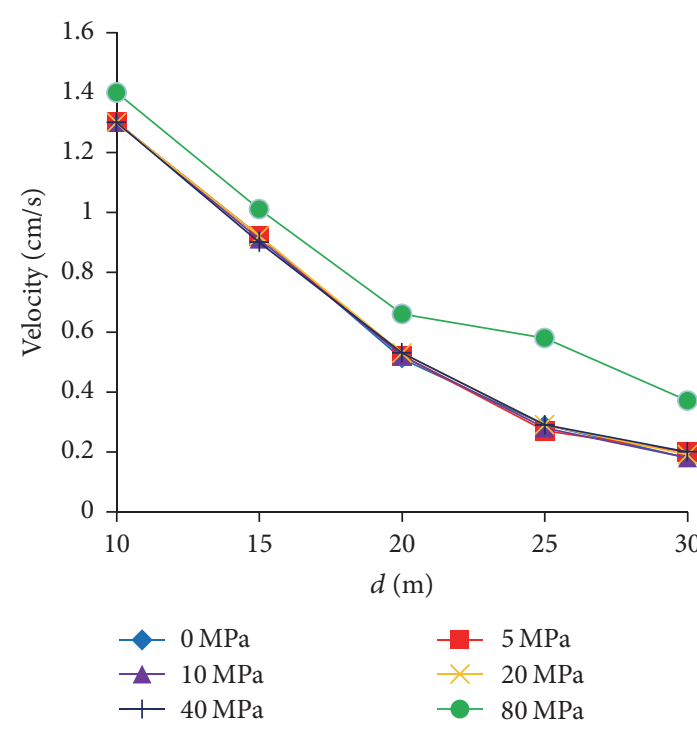

(b) Upright direction $Y$

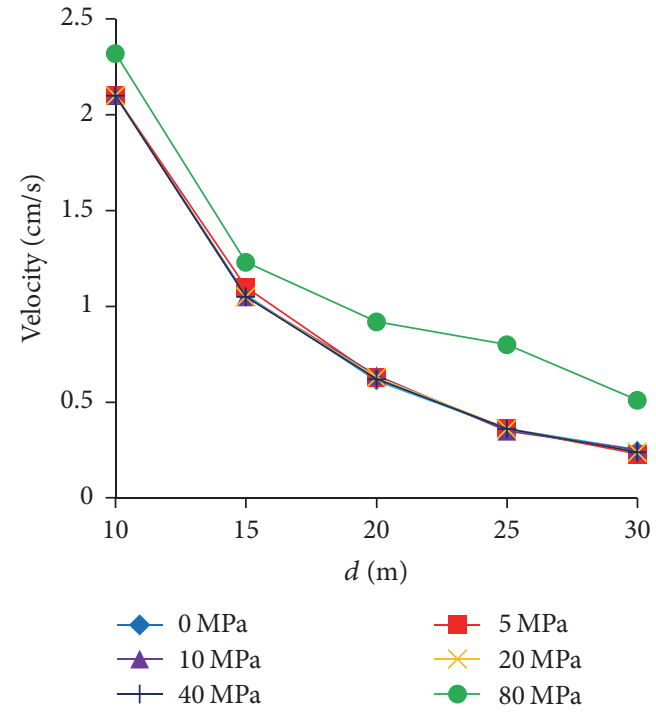

(c) Parallels to tunnel axis direction $Z$

FIGURE 13: The comparison of vibration velocity in the same measuring point under different crustal stress.

is applied, the penetrating cracks could be much easier to form among blast holes and the damage to surrounding rocks is rather small.

\subsection{The Analysis of Blast Vibration and Crack Forming under} Different Crustal Stress. According to the analysis of Sections 4.1 and 4.2 , when linear charging density is $70 \mathrm{~g} / \mathrm{m}$, whether in numerical simulation or on-site test, the blast vibration velocity in near-field of blasting source could be assured to meet the safety requirements. Moreover, the cracks forming among smooth blasting holes could be guaranteed and the damage to surrounding rock is lowered in certain extent when the density is in such value. Supposing the value of linear charging density is $70 \mathrm{~g} / \mathrm{m}$, the proportion of the horizontal crustal stress and vertical crustal stress is setting $1: 1$ in value of $0 \mathrm{MPa}, 5 \mathrm{MPa}, 10 \mathrm{MPa}, 20 \mathrm{MPa}, 40 \mathrm{MPa}$, and $80 \mathrm{MPa}$, respectively. Taking into account the blasting vibration velocity of the same measuring points under different crustal stress and the cracks forming between the smooth blasting holes, the blast vibration velocity of measuring points could be worked out by numerical calculation as shown in Figure 13.
According to the vibration velocity in three directions shown in figures, the vibration velocity of measuring points in direction $X$ perpendicular to tunnel axis is in the largest value while that in upright direction $Y$ is the smallest. When the crustal stress is $0-40 \mathrm{MPa}$, the changing rule of vibration velocity of the same measuring point in the same directions consists with each other, which indicates that there is no apparent relation between vibration velocity of surrounding rock in near-field of blasting and magnitude of crustal stress under the identical charging amount and charging structures. When the crustal stress is $80 \mathrm{MPa}$, the vibration velocities of measuring points in three directions all increase, which indicates that when the crustal stress reaches a certain value, a large amount of potential energy in underground rock mass is released. When explosive loads exert force disturbances on rock mass, larger vibration has been produced under the effect of blasting kinetic energy and crustal stress potential energy on the rock mass nearby blasting source.

According to the calculation and analysis in Section 4.2, only exert stress in $Z$ direction parallel to tunnel axis on two-dimensional plane model. Thus, the stress of $Z$ direction 
TABLE 5: Stress values of $Z$ direction of the same measuring points under different crustal stress.

\begin{tabular}{|c|c|c|c|c|c|c|}
\hline \multirow{2}{*}{ Crustal stress/MPa } & \multicolumn{5}{|c|}{ Measuring points } & \multirow{2}{*}{ Average value/MPa } \\
\hline & $1^{\#}$ & $2^{\#}$ & $3^{\#}$ & $4^{\#}$ & $5^{\#}$ & \\
\hline 0 & 0 & 0 & 0 & 0 & 0 & 0 \\
\hline 5 & 4.65 & 4.57 & 4.60 & 4.64 & 4.64 & 4.62 \\
\hline 10 & 9.30 & 9.13 & 9.18 & 9.28 & 9.28 & 9.23 \\
\hline 20 & 18.60 & 18.26 & 18.38 & 18.56 & 18.55 & 18.47 \\
\hline 40 & 37.18 & 36.50 & 36.73 & 37.09 & 37.07 & 36.91 \\
\hline 80 & 74.90 & 73.70 & 75.20 & 76.73 & 77.80 & 75.67 \\
\hline
\end{tabular}

TABLE 6: The damage depth, area of surrounding rocks, and the crushing rate of excavated rock mass.

\begin{tabular}{lccccc}
\hline Crustal stress/MPa & 0 & 5 & 10 & 20 & 40 \\
\hline Damage depth of surrounding rocks/cm & $>50$ & $>50$ & $\approx 20$ & $\approx 10$ & $<10$ \\
Damage area of surrounding rocks/\% & $>50$ & $>50$ & $\approx 40$ & $\approx 20$ & $<10$ \\
Crushing rate of excavated rock mass/\% & $>75$ & $>70$ & $>70$ & $>50$ & $<6.7$ \\
\hline
\end{tabular}

on the same measuring point is selected to exert on twodimensional plane model as the original crustal stress. Table 5 shows the value of stress in $Z$ direction of same measuring points but different crustal stress.

Keeping the charging of blast holes in a certain amount and exerting the average value of stress in $Z$ direction that is worked out in Table 5 on two-dimensional plane model, the crack forming figure is worked out under different stresses as shown in Figure 14. The damage depth and area of surrounding rocks and the crushing rate of excavated rock mass are summarized as shown in Table 6.

As shown in Figure 14, the smaller the crustal stress is, the larger the crushing degree of rock mass and the damage to surrounding rocks are. When crustal stress increases and although the damage to surrounding rocks reduces, the crushing degree of rock mass lowers as well, so the required crushing rate of excavated rock mass on site could not be reached. With such charging structure and charging amount, larger crushing degree and low damage can be achieved, only when the exerted crustal stress is $20 \mathrm{MPa}$, known as the most approximate value to crustal stress on site, and the effect of larger crushing degree of rock mass and the lower damage to surrounding rocks near blast holes can be achieved, which indicates that charging amount must be adjusted correspondingly according to different crustal stress when the underground cavern is excavated by blasting.

According to the reference of Figure 13 and Table 6, when the crustal stress is $0-40 \mathrm{MPa}$, the charging amount of blast holes should be increased followed by the increase of crustal stress so as to meet the requirement of blasting excavation. When the crustal stress continues to increase, the vibration velocity of same measuring points on moderate and far area of blasting under the same charging amount will be increased, which could need the reduction of charge amount. However, the lower crushing degree of rock mass indicates the increase of charge amount. Due to the above analysis, in the blasting excavation conducted in underground caverns where the crustal stress is rather large, it is not simply the matter of increase or reduction of the charge amount but rather the new layout of blast holes as well as the adjustment of charge portion of smooth blasting holes and auxiliary holes.

\section{Conclusion}

The following conclusions could be drawn according to the analytical comparison of dynamic finite element calculation and on-site test:

(1) The vibration velocity test of three directions of surrounding rocks in moderate and far area blasting excavation of rock-anchored beams found out that the vibration velocity of rock mass perpendicular to the blasting excavation surface is the largest which should be used as the reference of vibration velocity control in rock mass excavation.

(2) The numerical simulation and on-site test indicate that when grooved and circular blast holes blast under the same charge amount, the grooved one is proved to carry out fine energy gathering effect as well as reduce the damage to surrounding rocks on a certain extent.

(3) Research on blasting excavation of underground caverns under different crustal stress found that, in identical charge amount, the crushing degree of rock mass and the damage to surrounding rocks decreases with the increase of crustal stress. When crustal stress is $0-40 \mathrm{MPa}$, the blasting vibration velocities of moderate and far area of rock mass approximate and when it reaches $80 \mathrm{MPa}$, the blasting vibration velocity on the same measuring point increases, so adjustments of blast holes layout and charge amount need to be done based on different crustal stress.

Due to the absence of practical situation of fine blasting project of rock-anchored beam excavation on underground caverns in high crustal stress, the results of numerical simulation could not be proved. Experiments and researches on such problem will be continued. 


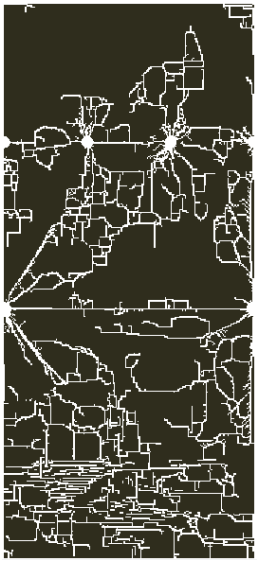

(a) $0 \mathrm{MPa}$

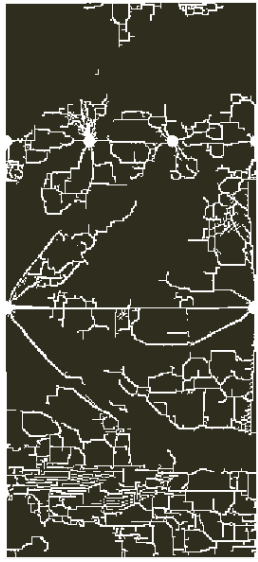

(b) $5 \mathrm{MPa}$

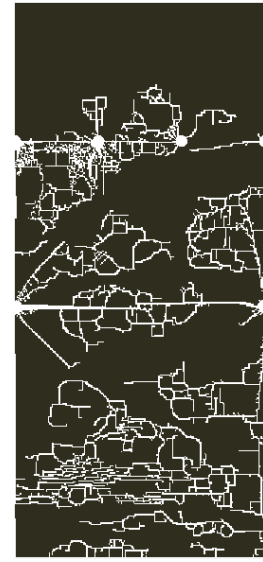

(c) $10 \mathrm{MPa}$

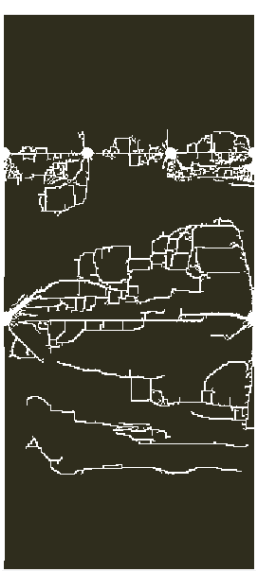

(d) $20 \mathrm{MPa}$

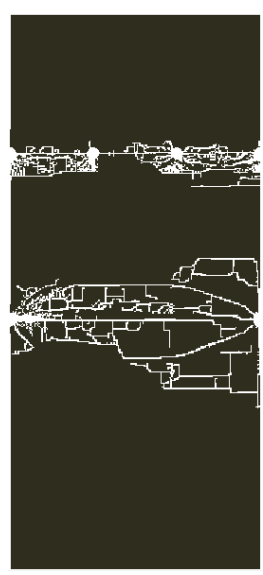

(e) $40 \mathrm{MPa}$

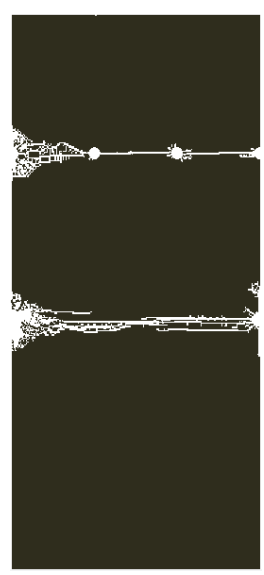

(f) $80 \mathrm{MPa}$

FIGURE 14: The crack forming diagram of rock mass under different crustal stress.

\section{Conflicts of Interest}

The authors declare that they have no conflicts of interest.

\section{Acknowledgments}

This work is supported by the National Natural Science Foundation of China (51274157 and 51309183), PLA University of Science and Technology (no. DPMEIKF201410), the Open Research Fund of State Key Laboratory of Geomechanics and Geotechnical Engineering, Institute of Rock and Soil Mechanics, Chinese Academy of Sciences (Grant no. Z015005).

\section{References}

[1] R. Lien, J. Kristiansen, and L. S. Pran, "Suspended support for crane rails in Norwegian underground powerhouses," International Water Power and Dam Construction, vol. 42, no. 4, pp. 48-49, 1990.

[2] P. M. Johansen, Model Field Tests on Crane Rail Beams at Skjomen and Kvilldal Power Stations, Norwegian Geotechnical Institute, Oslo, Norway, 1984.

[3] R. D. Gill and D. S. Lawrenson, "Underground works at Kenya's kiambere project," International Water Power and Dam Construction, vol. 38, no. 5, pp. 13-16, 1986.

[4] N. Pelekis, B. Theodoulidis, I. Kopanakis, and Y. Theodoridis, "Literature review of spatio-temporal database models," Knowledge Engineering Review, vol. 19, no. 3, pp. 235-274, 2004.

[5] D. Shi, Y. Li, and S. Zhang, The Explicit Dynamic Analysis on the Basis of ANSYS/LS-DYNA 8.1, Tsinghua University Press, Beijing, China, 2004 (Chinese).

[6] B. Jinze, Theory Basis and Examples Analysis of LS-DYNA 3D, Science Press, Beijing, China, 2005 (Chinese).

[7] G. Ling, Y. Chen, and W. Huang, "A classification method of spatio-temporal data model," in Proceedings of the Nationwide Cartography and GIS Academic Conferences, pp. 734-740, 2004.

[8] G. W. Ma, H. Hao, and Y. X. Zhou, "Modeling of wave propagation induced by underground explosion," Computers and Geotechnics, vol. 22, no. 3-4, pp. 283-303, 1998.
[9] C. Wu, Y. Lu, and H. Hao, "Numerical prediction of blastinduced stress wave from large-scale underground explosion," International Journal for Numerical and Analytical Methods in Geomechanics, vol. 28, no. 1, pp. 93-109, 2004.

[10] J. Toraño, R. Rodríguez, I. Diego, J. M. Rivas, and M. D. Casal, "FEM models including randomness and its application to the blasting vibrations prediction," Computers and Geotechnics, vol. 33 , no. 1 , pp. 15-28, 2006.

[11] H. Ding and Z. Zheng, "Source model for blasting vibration," Science in China, Series E: Technological Sciences, vol. 45, no. 4, pp. 395-407, 2002.

[12] D. S. Preece and B. J. Thorne, "A study of detonation timing and fragmentation using 3-D finite element techniques and a damage constitutive model," in Rock Fragmentation by Blasting, B. Mohanty, Ed., pp. 147-156, Balkema, Rotterdam, The Netherlands, 1996.

[13] W. Lu, J. Yang, P. Yan et al., "Dynamic response of rock mass induced by the transient release of in-situ stress," International Journal of Rock Mechanics and Mining Sciences, vol. 53, pp. 129141, 2012.

[14] L. X. Xie, W. B. Lu, Q. B. Zhang, Q. H. Jiang, G. H. Wang, and J. Zhao, "Damage evolution mechanisms of rock in deep tunnels induced by cut blasting," Tunnelling and Underground Space Technology, vol. 58, pp. 257-270, 2016.

[15] H. Xu, W. Lu, and X. Zhou, "An equivalent approach for acting blasting load in dynamic finite element simulation of blasting vibration," Engineering Journal of Wuhan University, vol. 41, no. 1, pp. 67-71, 2008 (Chinese).

[16] X. Xia, H.-B. Li, J.-R. Li, K.-Q. Xiao, H. Tang, and G.-W. Ma, "Numerical simulation of blast-induced cracks in rock," Rock and Soil Mechanics, vol. 27, no. 11, pp. 1987-1991, 2006.

[17] R. Yang, W. F. Bawden, and P. D. Katsabanis, "A new constitutive model for blast damage," International Journal of Rock Mechanics and Mining Sciences and Geomechanics, vol. 33, no. 3, pp. 245-254, 1996.

[18] M. Khandelwal and T. N. Singh, "Prediction of blast-induced ground vibration using artificial neural network," International Journal of Rock Mechanics and Mining Sciences, vol. 46, no. 7, pp. 1214-1222, 2009.

[19] D. Johansson and F. Ouchterlony, "Shock wave interactions in rock blasting: the use of short delays to improve fragmentation 
in model-scale," Rock Mechanics and Rock Engineering, vol. 46, no. 1, pp. 1-18, 2013.

[20] The Construction Bidding Documents with Civil Engineering and Metal Structure Installation Project on the Right Bank Diversion Generating System of Jinsha River Baihetan Hydropower Station, China's Hydropower Consulting Group East China Survey Design and Research Institute, 2013 (Chinese).

[21] E. L. Lee, H. C. Hornig, and J. W. Kury, "Lawrence Livermore laboratory report," Tech. Rep. UCRL-50442, 1986.

[22] W.-B. Lu, Y. Luo, M. Chen, and D.-Q. Shu, "An introduction to Chinese safety regulations for blasting vibration," Environmental Earth Sciences, vol. 67, no. 7, pp. 1951-1959, 2012.

[23] Q. Dong, X. Li, and Y. Luo, "Numerical simulation of damage characteristics of underground cavern smooth blasting excavation based on the improved KUS model," Electronic Journal of Geotechnical Engineering, vol. 21, no. 19, pp. 6381-6392, 2016, http://ejge.com. 


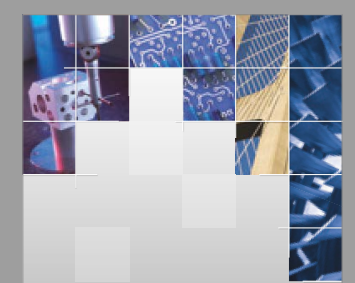

\section{Enfincering}
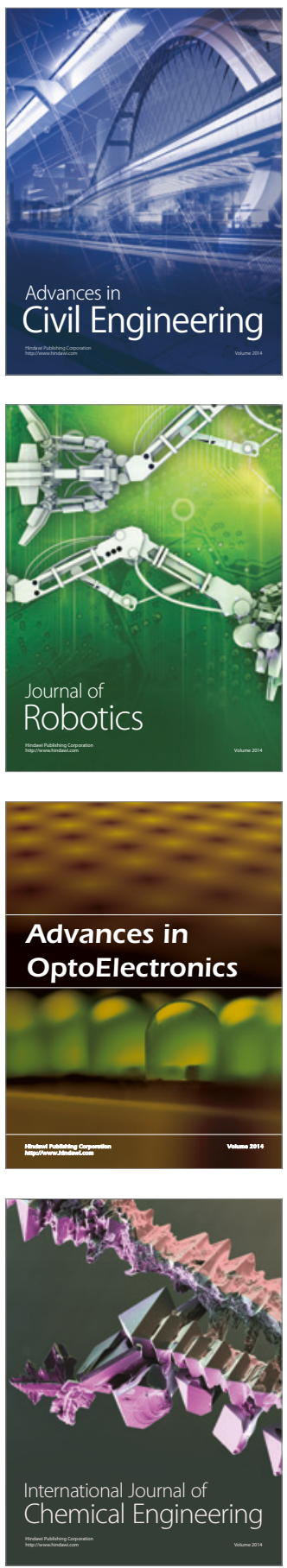

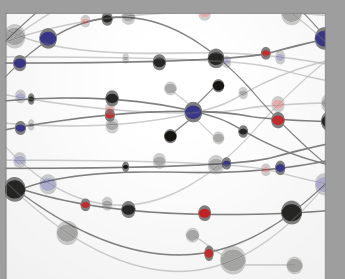

The Scientific World Journal

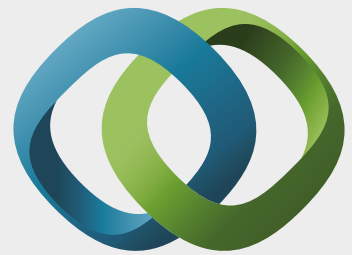

\section{Hindawi}

Submit your manuscripts at

https://www.hindawi.com
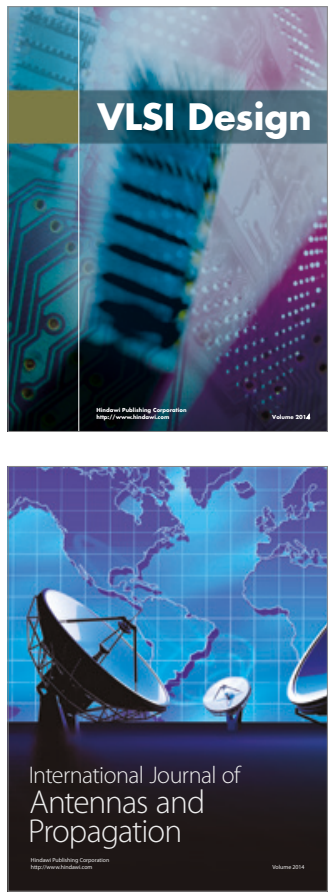

\section{Rotating}

Machinery
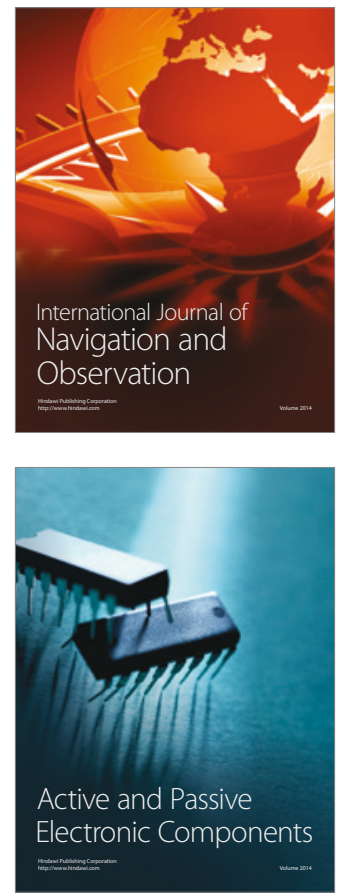
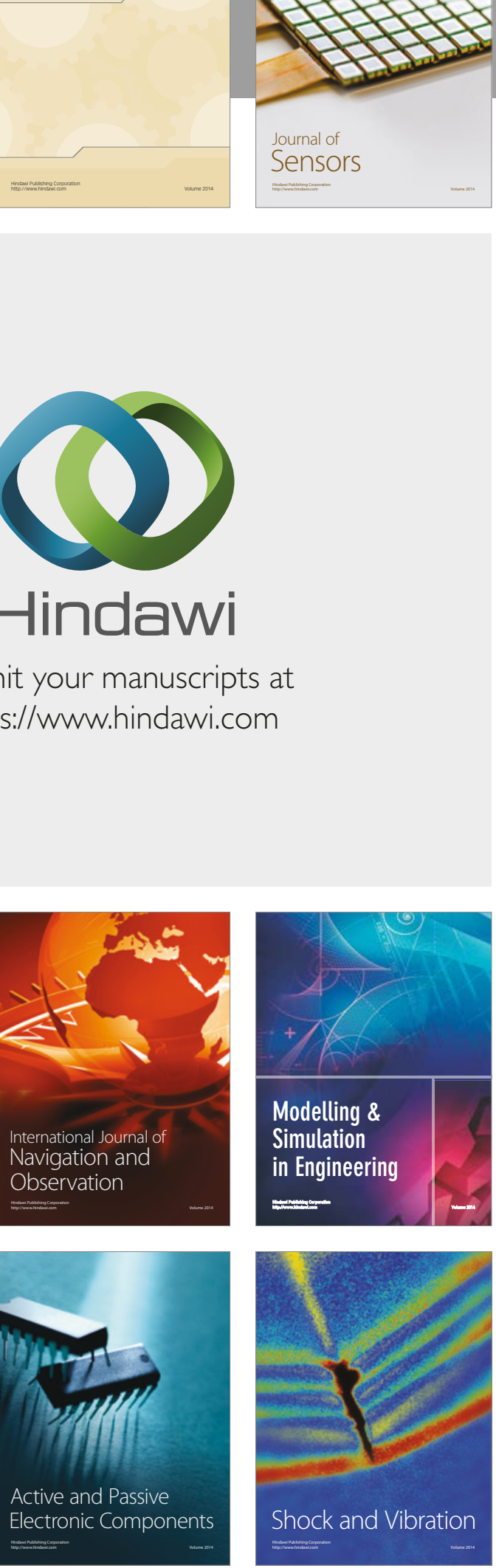
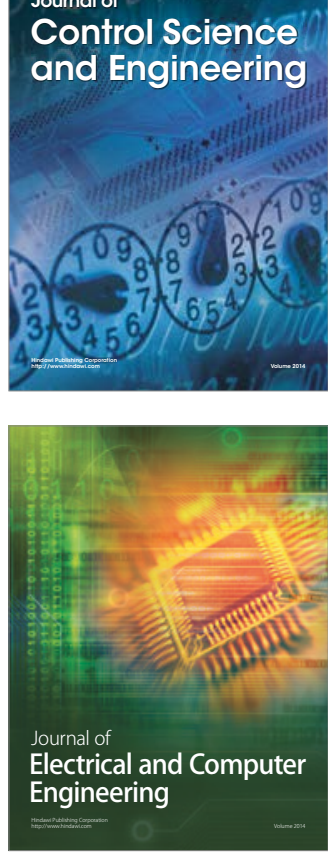

Distributed

Journal of

Control Science

and Engineering
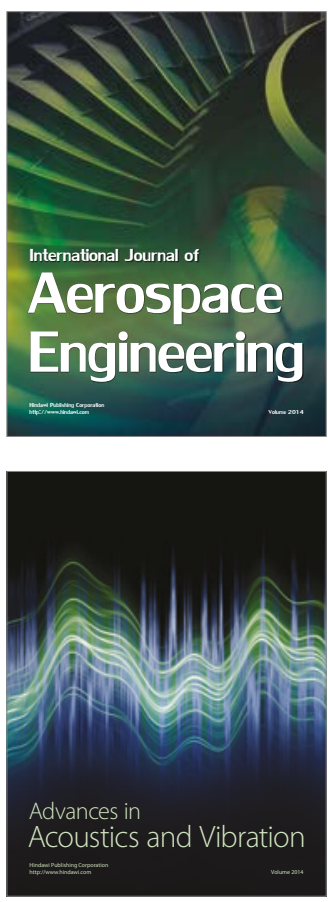

Sensor Networks 